\title{
Primary Care Clinicians Evaluate Integrated and Referral Models of Behavioral Health Care For Older Adults: Results From a Multisite Effectiveness Trial (PRISM-E)
}

\author{
Joseph J. Gallo, MD, MPH \\ Cynthia Zubritsky, $\mathrm{PbD}^{2}$ \\ James Maxwell, $P b D^{3}$ \\ Michael Nazar, $M D^{4}$ \\ Hillary R. Bogner, MD, MSCE ${ }^{1}$ \\ Louise M. Quijano, CSW-R \\ Heidi J. Syropoulos, MD, $C M D^{6}$ \\ Karen L. Cheal, MPH \\ Hongtu Chen, $\mathrm{PbD}^{7}$ \\ Herman Sanchez ${ }^{7}$ \\ Jobn Dodson ${ }^{7}$ \\ Sue E. Levkoff, $S c D,{ }^{7}$ and the \\ PRISM-E Investigators \\ 'Department of Family Practice and \\ Community Medicine, University of \\ Pennsylvania, Philadelphia, $\mathrm{Pa}$ \\ ${ }^{2}$ Center for Mental Health Policy and Research, \\ University of Pennsylvania, Philadelphia, Pa \\ ${ }^{3} J S I$ Research and Training Institute, Boston, Mass \\ ${ }^{4}$ Unity Health System, Rochester, NY \\ ${ }^{5}$ Unity Health System, Cypress, Tex \\ ${ }^{6}$ Cleveland Clinic Florida, Weston, Fla \\ ${ }^{7}$ Department of Psychiatry, Brigham and \\ Women's Hospital, Boston, Mass
}

Conflicts of interest: none reported

\section{CORRESPONDING AUTHOR}

Joseph J. Gallo, MD, MPH

Department of Family Practice and

Community Medicine

University of Pennsylvania

3400 Spruce Street

2 Gates Building

Philadelphia, PA 19104

jjgallo@mail.med.upenn.edu

\begin{abstract}
BACKGROUND Recent studies have shown that integrated behavioral health services for older adults in primary care improves health outcomes. No study, however, has asked the opinions of clinicians whose patients actually experienced integrated rather than enhanced referral care for depression and other conditions.

METHOD The Primary Care Research in Substance Abuse and Mental Health for the Elderly (PRISM-E) study was a randomized trial comparing integrated behavioral health care with enhanced referral care in primary care settings across the United States. Primary care clinicians at each participating site were asked whether integrated or enhanced referral care was preferred across a variety of components of care. Managers also completed questionnaires related to the process of care at each site.

RESULTS Almost all primary care clinicians $(n=127)$ stated that integrated care led to better communication between primary care clinicians and mental health specialists (93\%), less stigma for patients (93\%), and better coordination of mental and physical care (92\%). Fewer thought that integrated care led to better management of depression (64\%), anxiety (76\%), or alcohol problems (66\%). At sites in which the clinicians were rated as participating in mental health care, integrated care was highly rated as improving communication between specialists in mental health and primary care.
\end{abstract}

CONCLUSIONS Among primary care clinicians who cared for patients that received integrated care or enhanced referral care, integrated care was preferred for many aspects of mental health care.

Ann Fam Med 2004;2:305-309. DOI: 10.1370/afm.116.

\section{INTRODUCTION}

$\mathrm{T}$ o address patient, physician, and health system barriers to adequate care of depression and other mental health conditions of late life, innovative models are being tested to enhance the recognition and management of mental health problems in primary care. ${ }^{1-3}$ The Primary Care Research in Substance Abuse and Mental Health for the Elderly (PRISME) study was a multisite effectiveness trial designed to assess the use of a mental health and substance abuse (MH/SA) specialist co-located in the primary care practice to enhance treatment (the integrated care model) and the use of direct referral to specialty care (the enhanced referral model) for older adults with depression, anxiety, or alcohol use problems. We asked the clinicians to offer their perspectives on the specific interventions tested in PRISM-E. Given the heterogeneity of how primary care clinicians manage depression, ${ }^{4}$ it is important to be aware of systems of care that clinicians 
themselves think might work better. We believe primary care clinicians are important stakeholders in improving practice, and their opinions matter.

Our study differs from previous studies of attitudes of primary care clinicians regarding $\mathrm{MH} / \mathrm{SA}$ treatment given to patients in primary care. First, most studies have focused on depression, ${ }^{5-7}$ whereas we were able to examine several conditions that affect older adults in relation to primary health care. Second, we have focused on the mental health care of older adults, in contrast with other studies that have not considered the specific needs of older persons. ${ }^{5-7}$ Most importantly, unlike studies that elicit opinions of primary care clinicians, ${ }^{5,6,8-10}$ we specifically asked these clinicians about the effect of the integrated and enhanced referral models on the care of patients for whom the participating clinicians had clinical responsibility. No other study has asked clinicians about the preferences for new models of mental health care for older persons who were actually under their care.

\section{METHODS}

\section{The PRISM-E Study}

In the PRISM-E study, all patients aged 65 years and older were initially seen by or referred to the study by their primary care clinician, and those eligible for the study were subsequently randomized to treatment in 1 of the 2 models. The integrated model consisted of the co-location of $\mathrm{MH} / \mathrm{SA}$ specialists and services within primary care practices so that the primary care clinicians could play a more active role in treatment. The enhanced referral model encompassed referral to a separate mental health or substance abuse specialty clinic. The referral model was enhanced with transportation, case management, and other services to engage elderly patients in treatment. A total of 54 integrated and referral clinics operated within 11 study sites. Local institutional review boards at each site reviewed and approved the study protocol. Methods are described in detail elsewhere. ${ }^{11}$

\section{Measurement Strategy}

The survey was designed to assess important elements of $\mathrm{MH} / \mathrm{SA}$ care among clinicians who had actually experienced integrated or enhanced referral care with patients. All clinic primary care clinicians who had at least 1 study patient and who were, at the time of the survey, employed by the participating clinic were approached to complete the survey instrument. Most clinicians had experience with both models of care and hence responded to all survey questions, but clinicians at clinics from 3 Veterans Administration sites (Little Rock, Madison, and Chicago) only had experience with 1 model (integrated or enhanced referral) because of a different randomization scheme; the primary care clinicians from those sites responded only to questions pertaining to the model in use at their clinic. A total of 153 clinicians from the 11 study sites participating in the PRISM-E study were approached with the survey. Of this number, 127 returned completed survey instruments (response rate $83 \%$ ).

To document any heterogeneity between the integrated and enhanced referral models of care at different sites, a clinic-level process evaluation was developed and implemented at each study site. Office managers at each of the 54 clinics completed a detailed process evaluation that documented clinical care at the study sites. The purpose of the process evaluation was to ascertain which specific clinic features might contribute to the success or failure of the models.

\section{Analytic Strategy}

We tested whether the proportions of primary care clinicians preferring the integrated and enhanced referral models were significantly different from $50 \%$ by using a chi-square test of proportions (ie, no preference for one model of care to another). We performed bivariate chi-square analyses to examine possible clinician factors related to these preferences (variables were dichotomized to permit the calculation of odds ratios to facilitate interpretation). Because preference for integrated care to enhanced referral care might reflect differing accessibility of $\mathrm{MH} / \mathrm{SA}$ specialists at each site rather than a preference for integrated care as such, we used accessibility ratings of $\mathrm{MH} / \mathrm{SA}$ specialists obtained from the process evaluation to control for any differences across clinics (using tests of homogeneity of odds ratios across strata). ${ }^{12}$ Finally, we examined the relation between clinician participation in counseling and pharmacologic management and the clinicians' rating of communication between sectors in integrated care.

\section{RESULTS}

\section{Study Sample}

The mean age of the 127 clinicians who completed a survey was 44 years (SD 10 years). With regard to medical specialty, $52 \%$ of clinicians were internal medicine physicians and $32 \%$ were family or general practice physicians. Eighteen percent of respondents were nurse practitioners or physician assistants.

\section{Preferences for Integrated Care or Enhanced Referral Care}

Clinicians strongly preferred integrated care to enhanced referral care for all the dimensions assessed (Table 1).

We noted that sex and specialty of the clinician were 


\begin{tabular}{|c|c|c|}
\hline Treatment Aspect & $\begin{array}{l}\text { Integrated Care } \\
\text { Preferred* } \\
\text { No. (\%) }\end{array}$ & $P$ Value $^{\dagger}$ \\
\hline Better communication & $113(92.6)$ & $<.0001$ \\
\hline More comprehensive services & $74(61.7)$ & .0106 \\
\hline Better management of depression & $77(64.2)$ & .0019 \\
\hline Better management of anxiety & $91(75.8)$ & $<.0001$ \\
\hline Better management of alcohol abuse & $78(65.5)$ & $<.001$ \\
\hline More convenient services for patients & $106(87.6)$ & $<.0001$ \\
\hline Less stigma for patients & $111(92.5)$ & $<.0001$ \\
\hline $\begin{array}{l}\text { Better coordination of mental and physical } \\
\text { care }\end{array}$ & $109(91.6)$ & $<.0001$ \\
\hline Quicker appointments for mental health & $102(85.7)$ & $<.0001$ \\
\hline Better health education & $102(88)$ & $<.0001$ \\
\hline \multicolumn{3}{|c|}{$\begin{array}{l}\text { * Some data missing due to item nonresponse. } \\
\text { †P values represent the statistical test for whether the proportion preferring integrated care } \\
\text { equaled } 50 \% \text {. }\end{array}$} \\
\hline
\end{tabular}

Table 2. Clinician Rating of Communication Between Clinicians and MH/SA Specialists, by Clinician Participation in Management

\begin{tabular}{|c|c|c|}
\hline $\begin{array}{l}\text { Areas Clinicians More } \\
\text { Likely to Agree Frequent } \\
\text { Communication Occurs }\end{array}$ & $\begin{array}{l}\text { Participates } \\
\text { in Counseling } \\
\text { OR }(95 \% \mathrm{Cl})\end{array}$ & $\begin{array}{c}\text { Participates in } \\
\text { Psychopharmacology } \\
\text { Management } \\
\text { OR }(95 \% \mathrm{Cl})\end{array}$ \\
\hline Results of $\mathrm{MH} / \mathrm{SA}$ diagnosis & $8.2(2.5-26)$ & $7.8(2.4-25)$ \\
\hline Medical diagnosis, condition & $1.5(0.52-4.4)$ & $1.8(0.67-4.9)$ \\
\hline Medical care plan & $1.4(0.52-3.9)$ & $0.97(0.36-2.6)$ \\
\hline MH/SA care plan & $3.5(1.2-10.6)$ & $4.3(1.5-12.7)$ \\
\hline $\mathrm{MH} / \mathrm{SA}$ progress and follow-up & $3.3(1.1-9.2)$ & $2.9(1.1-7.9)$ \\
\hline
\end{tabular}

\section{Controlling for Ratings of Access to MH/SA Specialists in the Referral Arm}

There was a significant association between access to $\mathrm{MH} / \mathrm{SA}$ specialists in the integrated arm and preference for the integrated arm for the treatment of depression, even after controlling for access to $\mathrm{MH} / \mathrm{SA}$ specialists in the enhanced referral arm $(P=.007)$. In particular, primary care clinicians at clinics rating access to mental health specialists in the enhanced referral arm as neutral to difficult were 8 times more likely to prefer integrated care to enhanced referral care for the management of depression $(\mathrm{OR}=8.4 ; 95 \% \mathrm{CI}$, 2-35) when access to mental health specialists in the integrated arm was rated as easy.

\section{Shared Care and Improved Communi- cation in the Integrated Model}

Less than $50 \%$ of primary care clinicians rated communication between themselves and $\mathrm{MH} / \mathrm{SA}$ specialists in the enhanced referral arm as occurring frequently compared with $80 \%$ in the integrated arm. Participation of the primary care clinician in mental health care (counseling and psychopharmacology management) was significantly associated with believing that there was frequent communication in the integrated model between the clinician and the MH/SA specialist (Table 2).

\section{DISCUSSION}

The primary care clinicians in our study expressed a strong preference for integrated care rather than enhanced referral care for

significantly associated with preferences. Specifically, women clinicians were more likely than men to perceive that integrated care offered more advantages than enhanced referral care for comprehensiveness of services (odds ratio [OR] $=2.9$ for women compared with men, 95\% confidence interval $[\mathrm{CI}], 1.3-6.7)$, for management of depression $(\mathrm{OR}=3.3,95 \% \mathrm{CI}$, 1.2-8.9), more convenient services for patients (OR $=9.4,95 \% \mathrm{CI}, 1.5-58)$, and quicker appointments for mental health $(\mathrm{OR}=6.4,95 \% \mathrm{CI}, 1.2-34)$. Compared with other clinicians, family physicians were more likely to perceive that integrated care was better than enhanced referral care for comprehensiveness of services $(\mathrm{OR}=3.4$ for family physicians compared with other clinicians, $95 \% \mathrm{CI}, 1.1,10.6)$ and for better management of depression $(\mathrm{OR}=6.5$ for family physicians compared with other clinicians, $95 \% \mathrm{CI}, 1.8-24)$. older adults with psychiatric disturbances. Specifically, clinicians thought that older adults were more likely to experience greater convenience and less stigma if the mental health services were integrated with the primary care setting. When the primary care clinicians were more involved in counseling and management of medications in the integrated arm, communication regarding the $\mathrm{MH} / \mathrm{SA}$ care was much more likely to be rated highly. Although the referral condition was enhanced with transportation and other services to engage older adults in treatment, the clinicians still preferred to have $\mathrm{MH} /$ SA care integrated into the primary health care setting.

Like all surveys, our results are based on the opinions of clinicians in practices that participated in a research project and might not be representative of all primary care practices. Our sample size was relatively small compared with other surveys. ${ }^{4,9,13}$ Although our response rate for the survey was high, clinicians who 
returned a survey instrument might have differed from others in important ways.

Despite limitations, our results about the preference of primary care clinicians for integrated rather than enhanced referral care deserve attention because our study of clinician attitudes differs in several important ways from other surveys carried out in primary care settings. First, we were able to focus our attention on 2 specific models of mental health service integration into primary care settings; namely, an integrated model that included a primary care-based mental health specialist and direct referral. Clinicians in our study were asked to comment on models of care they had actually experienced as a component of the PRISM-E study in contrast to hypothetical situations. Second, organizational-level data were available from parallel, standardized process evaluations carried out at each participating site so that we could relate practice characteristics from process evaluations to the survey responses from clinicians. Third, no survey to date has examined the perceptions of primary care clinicians regarding integrated mental health care for older persons under their care who had actually experienced one model of services organization or another.

Overall, responding clinicians preferred integrated care to enhanced referral care. Consistently, the added resources of integrated care were perceived as having enhanced aspects of primary health care, such as communication with the $\mathrm{MH} / \mathrm{SA}$ specialist, convenience for patients, and less stigma for patients who require mental health care.

Women physicians and family physicians were more likely to prefer integrated care for improving some aspects of the care of older adults with mental disturbances. Previous studies have reported differences in the therapeutic stance of family physicians and internists in the treatment of depression. For example, Gallo and colleagues ${ }^{4}$ compared responses of family physicians and internists who had participated in an effectiveness trial of depression treatment in primary care settings. ${ }^{14}$ Family physicians were about twice as likely as internists to report that they would prescribe an antidepressant for a patient with moderate to severe depression, whereas the internists were about twice as likely to report they would refer the patient. Whether because of training or characteristics related to specialty choice, family physicians generally report feeling more comfortable than internists with the responsibility for depression management. ${ }^{4,13,15-17}$ Primary care clinicians who actively provided counseling or pharmacologic management of depression were much more likely to rate communication about several aspects of $\mathrm{MH} / \mathrm{SA}$ care highly. The association between active participation in care and improved communication suggests that the integrated model affords the clinician the ability to take a more active role in the management of $\mathrm{MH} / \mathrm{SA}$ conditions

Preference for integrated rather than enhanced referral care for the management of depression was strongly associated with the accessibility of the MH/SA specialist in the integrated arm but not with that in the enhanced referral arm. This finding suggests that clinicians preferred a care model affording them close access to an MH/SA specialist and possibly the opportunity to take a more active role in treatment.

If we are to deal with depression as a public health problem, we need to address the primary health care setting. ${ }^{18,19}$ Numerous models for integrating mental health care into primary health care settings have been evaluated in randomized trials $s^{1-3,20,21}$ or discussed in anecdotal reports. ${ }^{22-24}$ For many aspects of care, clinicians in PRISM-E preferred mental health care to be integrated with primary health care for older patients with psychiatric disturbances. The integrated intervention was feasible in the community practices across the United States in diverse health care environments that participated in PRISM-E. Given the expansion of group practice, we think the intervention could be feasible in many practices beyond those that participated in PRISM-E.

\section{To read or post commentaries in response to this article, see it} online at http://www.annfammed.org/cgi/content/full/2/4/305.

Key words: Aged; depression; primary health care; health knowledge, attitudes, practice; professional practice; substance-related disorders/therapy; health services for the aged

Submitted July 7, 2003; submitted, revised, October 15, 2003; accepted November 24, 2003.

Funding support: PRISM-E is a collaborative research study funded by the Substance Abuse and Mental Health Services Administration (SAMH $\mathrm{SA})$, including its 3 centers: Center for Mental Health Services (CMHS), Center for Substance Abuse Treatment (CSAT), and the Center for Substance Abuse and Prevention (CSAP). The Department of Veteran's Affairs (VA), the Health Resources and Services Administration (HRSA), and the Centers for Medicare and Medicaid Services (CMS) provided additional support and funding. Dr. Bogner was supported by an Advanced Research Training Award from the American Academy of Family Physicians.

Acknowledgment: The PRISM-E investigators wish to thank Paul Wohlford, PhD, for acquiring Office of Management and Budget approval to conduct this survey.

PRISM-E Study Investigators (in alphabetical order): Carolyn Aoyama (HRSA), Pat Arean (Co-PI), Stephen Bartels (PI), Hongtu Chen (PI), Henry Chung (Co-PI), Marisue Cody (Co-PI), Giuseppe Costantino (PI), U. Nalla B. Durai (PI), Carroll Estes (PI), Susan Cooley (VA), Jack Fitzpatrick (Co-PI), Brian Goodman (Co-PI), Trevor Hadley (Co-PI), Tim Howell (Co-PI), Ira Katz (Co-PI), Joanne Kirchner (PI), Dean Krahn (PI), Sue Levkoff (PI), Karen Linkins (Co-PI), Maria Llorente (PI), Ann Mahony (SAMHSA), James Maxwell (Co-PI), Keith Miles (Co-PI), Robert Molokie (Co-PI), Jack McIntyre (PI), Elizabeth McDonel Herr (SAMHSA), Mike Nazar (Co-PI), Edwin Olsen (PI), David Oslin (PI), Tom Oxman (Co-PI), Andy Pomerantz (Co-PI), Louise Quijano (Co-PI), Pat Sabry (SAMHSA), William Van Stone (VA), Heidi Syropoulos (Co-PI), Cynthia Zubritsky (PI). 


\section{References}

1. Williams JW, Barrett J, Oxman T, et al. Treatment of dysthymia and minor depression in primary care: a randomized controlled trial in older adults. JAMA. 2000;284:1519-1526.

2. Fleming MF, Barry KL, Manwell LB, Johnson K, London R. Brief physician advice for problem alcohol drinkers: a randomized controlled trial in community-based primary care practices. JAMA. 1997;277:1039-1045.

3. Unutzer J, Katon W, Callahan CM, et al. Collaborative care management of late-life depression in the primary care setting: a randomized controlled trial. JAMA. 2002;288:2836-2845.

4. Gallo JJ, Meredith L, Gonzales J, et al. Do family physicians and internists differ in knowledge, beliefs, and self-reported approaches for depression? Int J Psych Medicine. 2002;32:1-20.

5. Shao WA, Williams JW, Lee S, Badgett RG, Aaronson B, Cornell JE. Knowledge and attitudes about depression among non-generalists and generalists. J Fam Practice. 1997;44:161-168.

6. Callahan CM, Nienaber NA, Hendrie HC, Tierney WM. Depression of elderly outpatients: primary care physicians' attitudes and practice patterns. J Gen Int Medicine. 1992;7:26-31.

7. Meredith L, Rubenstein LV, Rost K, et al. Treating depression in staffmodel versus network-model managed care organizations. J Gen Int Medicine. 1999;14:39-48.

8. Main DS, Lutz LJ, Barrett JE, Matthew J, Miller RS. The role of primary care clinician attitudes, beliefs, and training in the diagnosis and treatment of depression: a report from the Ambulatory Sentinel Practice Network. Arch Fam Medicine. 1993;2:1061-1066.

9. Gallo JJ, Ryan SD, Ford D. Attitudes, knowledge, and behavior of family physicians regarding depression in late life. Arch Fam Medicine. 1999;8:249-256.

10. Botega NJ, Silveira GM. General practitioners attitudes towards depression: a study in primary care setting in Brazil. Int J Soc Psychiatry. 1996;42:230-237.

11. Levkoff SE, Chen H, Coakley E, et al. Design and sample characteristics of the PRISM-E multisite randomized trial to improve behavioral health care for the elderly. J Aging Health. 2004;16:3-27.

12. Fleiss J. Statistical Methods for Rates and Proportions. 2nd ed. New York, NY: John Wiley \& Sons; 1981.
13. Williams JW, Rost K, Dietrich AJ, Ciotti M, Zyzanski S, Cornell J. Primary care physicians approach to depressive disorders: Effects of physician specialty and practice structure. Arch Fam Medicine. 1999;8:58-67.

14. Wells KB, Sherbourne C, Schoenbaum M, et al. Impact of disseminating quality improvement programs for depression in managed primary care: a randomized controlled trial. JAMA. 2000;283:212-220.

15. Glasser M, Gravdal JA. Assessment and treatment of geriatric depression in primary care settings. Arch Fam Medicine. 1997;6:433-438.

16. Banazak DA. Late-life depression in primary care: how well are we doing? J Gen Int Medicine. 1996;11:163-167.

17. Meredith LS, Wells KB, Camp P. Clinician specialty and treatment style for depressed outpatients with and without medical comorbidities. Arch Fam Medicine. 1994;3:1065-1072.

18. Kramer M, Simonsick E, Lima B, Levav I. The epidemiological basis for mental health care in primary health care: a case for action. In: Cooper B, Eastwood R, eds. Primary Health Care and Psychiatric Epidemiology. New York, NY: Tavistock/Routledge; 1992:69-98.

19. Gallo JJ, Coyne JC. The challenge of depression in late life: bridging science and service in primary care [editorial]. JAMA. 2000;284:1570-1572.

20. Callahan CM, Hendrie HC, Dittus RS, Brater DC, Hui SL, Tierney WM. Improving treatment of late life depression in primary care: a randomized clinical trial. J Am Geriat Society. 1994;42:839-846.

21. Schulberg HC, Block MR, Madonia MJ, et al. Treating major depression in primary care practice: eight-month clinical outcomes. Arch Gen Psychiatry. 1996;53:913-919.

22. Falloon IRH, Fadden G. Integrated Mental Health Care: A Comprehensive Community-Based Approach. New York, NY: Cambridge University Press; 1993.

23. Blount A, ed. Integrated Primary Care: The Future of Medical and Mental Health Collaboration. New York, NY: WW Norton \& Company; 1998.

24. Cummings NA, Cummings JL, Johnson JN, eds. Behavioral Health in Primary Care: A Guide for Clinical Integration. Madison, Conn: Psychosocial Press; 1997. 